\title{
Local Dental Committees' annual conference
}

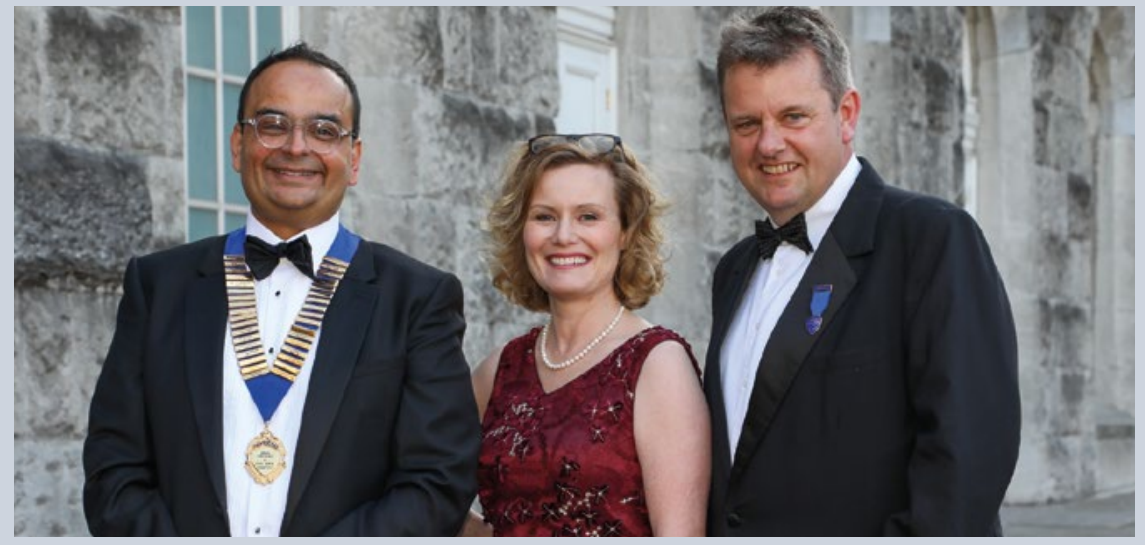

Vijay Sudra (Conference Chair 2019), Leah Farrell (Chair Elect) and Joe Hendron (Past Chair), at the LDCs' annual conference in Birmingham

The slow pace of contract reform and the lack of support for dentists experiencing stress were among the 34 motions raised at the Local Dental Committees' (LDCs) annual conference, held on 6-7 June 2019 in Birmingham.

The motion calling for a minimum UDA value of $£ 25$ was passed unanimously. During the debate, delegates heard that those involved in the contract reform pilots in Wales were already receiving this rate and their counterparts in England were seeking parity.

Delegates also voted unanimously for greater mental health support for dentists to be made available now and funded by all the health services across the UK.

Many representatives expressed concerns in a debate about the costs associated with the gradual phasing down and withdrawal of amalgam, which are expected to be borne by dentists. There was unanimous support for a motion calling on Department of Health and Social Care to fund in full all the additional costs incurred in this process, both in the short and long-term.

Conference also supported a motion calling for equity between the CQC rates paid by corporates and general dental practitioners on the high street. They voted unanimously for an end to the single owner subsidy.

Delegates rejected calls from Cornwall LDC that the General Dental Practice Committee (GDPC) should adopt a view that NHS dentistry should only be funded for community and hospital services.
The escalation of dental charges in England, relative to Wales, was also raised amid concerns that these were masking cuts in state funding, as well as being unjust. Delegates heard that band 1 charges are 58\% more for patients in England than in Wales and there was a variance of $£ 70$ in band 3 charges between the two nations. There was unanimous support for a motion calling on the National Audit Office to investigate the disproportionate rise in charges in England.

Leading health economist, Stephen Tidman, held delegates' attention during a presentation on the consequences of the cash-limited dental budget in England that has not only radically reduced access for patients but also the numbers of dentists that provide NHS care.

Marco Mazevet of the French Dental Association provided an insight into the way dentistry works in France, by contrast to the UK, while Paul Batchelor spoke about the different models of state-funded dentistry across Europe.

Vijay Sudra, Chair of LDC Conference 2019, said: 'It was great to see such a diversity of opinions at this year's conference, and our guest speakers gave us lots to think about. I'm now handing over the reins of LDC Conference Chair to Leah Farrell, who is already leading on the organising of next year's event'.

Stuart Allan was elected as chair of LDC Conference 2021, and Vijay Sudra was elected as LDC conference representative to the GDPC.

\section{Here has been an advertisement.}

SPRINGERNATURE 